\title{
Symptomatic Increase in Intracranial Pressure Following Pancreatic Enzyme Replacement Therapy for Cystic Fibrosis
}

\author{
Samya Z. Nasr, $\mathrm{MD}^{1}{ }^{1}$ and Denise Schaffert, $\mathrm{MD}^{2}$
}

\begin{abstract}
Summary. A newly diagnosed 5-month-old infant with cystic fibrosis (CF) developed signs and symptoms of increased intracranial pressure (ICP) within days of starting pancreatic enzyme replacement therapy. Symptoms promptly resolved on two occasions after stopping enzyme replacement. At 10 months of age, enzyme replacement was well tolerated. Pediatr Pulmonol. 1995; 19:396-397. (c) 1995 Wiley-Liss, Inc.
\end{abstract}

Key words: Cystic fibrosis, intracranial pressure, pancreatic enzyme therapy.

\section{INTRODUCTION}

Asymptomatic elevations of intracranial pressure (ICP) and a bulging cranial fontanelle in children with cystic fibrosis (CF) have been attributed to vitamin A deficiency. ${ }^{1,2}$ They were described as a transient phenomenon following initiation of treatment for cystic fibrosis and improvement of the poor nutritional status. ${ }^{3-7}$ It was also speculated that intracranial pressure elevations may be associated with severe respiratory distress, ${ }^{8}$ and initiation of pancreatic enzyme replacement has been reported with asymptomatic bulging fontanelle. ${ }^{9}$

This report describes an infant with $\mathrm{CF}$ who developed symptomatic elevation of ICP within days of starting pancreatic replacement. Symptoms resolved on two occasions shortly after pancreatic enzymes were stopped. This case is of interest because the increase in intracranial pressure resulted in symptoms.

\section{CASE REPORT}

A 1-year-old Caucasian male was diagnosed as having cystic fibrosis at 5 months of age secondary to failure to thrive, pneumonia and a sweat chloride of $123 \mathrm{mEq} / \mathrm{L}$. He was homozygous for the mutation $\Delta F 508$. He was a product of a normal pregnancy. He was delivered by normal spontaneous vaginal delivery. Birth weight was $3.60 \mathrm{~kg}$ and length was $50 \mathrm{~cm}$. Length and weight had dropped from the 50th percentile and 75th percentile, respectively for age at birth to the tenth percentile and fifth percentile for age at diagnosis. When the diagnosis was made, treatment was started and included pancreatic enzyme replacement with Pancrease ${ }^{\circledR}$ (McNeil Pharmaceutical, Spring House, PA) in a dose of $700 \mathrm{IU} / \mathrm{kg} /$ feed (daily dose 4,200 IU/kg) and vitamin supplements. Two days after starting the above treatment, he began vomit- ing, followed by development of a bulging fontanelle and irritability. He was afebrile. He was admitted to a local hospital. CT scan of the head was normal, aside from the bulging fontanelle. Lumbar puncture was negative, however, the opening pressure was not measured. While in the hospital, the pancreatic supplements were stopped. The patient did well and the discharge diagnosis was increased intracranial pressure of unknown etiology. Pancreatic supplements were restarted prior to discharge. One day after discharge, he returned to the local hospital with the same symptoms, i.e., vomiting, bulging fontanelle, and irritability. CT of the head was repeated and was negative, as was an MRI. Lumbar puncture showed an opening pressure of $40-42 \mathrm{~cm} \mathrm{H}_{2} \mathrm{O}$ and a closing pressure of $10 \mathrm{~cm} \mathrm{H}_{2} \mathrm{O}$. The remaining $\mathrm{LP}$ results were negative. The patient improved during the hospitalization, while off pancreatic enzyme replacement. He was discharged home with a diagnosis of increased intracranial pressure, secondary to pancreatic enzyme supplements.

Pancreatic enzymes were withheld, and he was maintained on Pregestamil, with an accelerated growth pattern. Pancreatic supplements were restarted at 10 months of age after baby food was started and pancreatic insufficiency was apparent. He was placed on Pancrease ${ }^{\circledR}$, at a

From the 'University of Michigan Medical Center, Department of Pediatrics, Section of Pediatric Pulmonary Medicine, Ann Arbor, and ${ }^{2}$ Midland Child and Adolescent Center, Midland, Michigan.

Received August 30, 1994; (revision) accepted for publication March 5,1995

Addess correspondence and reprint requests to Dr. S.Z. Nasr, University of Michigan Medical Center, Department of Pediatrics, Section of Pediatric Pulmonary Medicine, 200 E. Hospital Drive, Ann Arbor, MI 48109-0718 
dose of $400 \mathrm{rU} / \mathrm{kg} / \mathrm{meal}$, with a total daily dose of 2,000 IU $/ \mathrm{kg}$. Since that time he has had no signs or symptoms of increased ICP.

\section{DISCUSSION}

Transient asymptomatic increased intracranial pressure shortly after initiation of treatment for cystic fibrosis has been reported repeatedly. ${ }^{1-9}$ The infants improved clinically and showed spontaneous resolution of the bulging fontanelle within a few weeks without interruption of $\mathrm{CF}$ treatment.

Our patient demonstrated significant signs and symptoms of increased intracranial pressure within days of starting the pancreatic enzyme replacement. Although these signs and symptoms resolved within 2 to 4 days after discontinuing therapy, they recurred within $24 \mathrm{hr}$ when the pancreatic enzymes were restarted. When the pancreatic insufficiency became obvious, the pancreatic enzyme supplementation (Pancrease ${ }^{\circledR}$ was used in both occasions) was restarted with no adverse effects.

The increased intracranial pressure in our patient was symptomatic and not self-limiting. To our knowledge, this has not been reported previously. The symptoms could be due to more severe CF disease, especially that the patient was found to be homozygous $\Delta F 508$, a mutation associated with severe pancreatic insufficiency. ${ }^{10}$

The mechanism of increased intracranial pressure in cystic fibrosis patients is complex and has been attributed to vitamin A deficiency, ${ }^{1,2}$ catch up brain growth, ${ }^{3-7}$ and severe respiratory distress. ${ }^{8}$ All of these causes seem unlikely in this case. The patient lacked xerophthalmia, corneal ulceration, anemia, and he lacked pathologic findings by skeletal X-ray. Also, the increased intracranial pressure reoccurred with resumption of pancreatic supplementation. The patient continued to grow appro- priately and he did not have respiratory distress at the time he developed a bulging fontanelle.

The transient nature and rapidity of onset of signs and symptoms on both occasions suggest that pancreatic supplementation played a major role in the etiology of increased intracranial pressure, especially since pancreatic supplement was the only elimination from the treatment protocol after reoccurrence of symptoms.

In conclusion, this case report suggests the association of increased intracranial pressure with pancreatic enzyme replacement in a newly diagnosed $\mathrm{CF}$ infant.

\section{REFERENCES}

1. Abernathy RS. Bulging fontanelle as presenting sign in cystic fibrosis-vitamin A metabolism and effect on cerebrospinal fluid pressure. Am J Dis Child. 1976; 130:1360-1362.

2. Keating JP, Feigin RD. Increased intracranial pressure associated with probable vitamin A deficiency in cystic fibrosis. Pediatrics $1970 ; 46: 41-46$.

3. Bray PF, Herbst JJ. Pseudotumor cerebri as a sign of "catchup" growth in cystic fibrosis. Am J Dis Child. 1973; 126:78-79.

4. Couch R, Camfield PR, Tibbles JAR. The changing picture of pseudotumor cerebri in children. Can J Neurol Sci. 1985; 12:4850.

5. Roach ES, Sinal SH. Increased intracranial pressure following treatment of cystic fibrosis. Pediatrics 1980; 66:662-663.

6. Sondheimer FK, Grossman H, Winchester P. Suture diastasis following rapid weight gain-Pseudopseudotumor cerebri. Arch Neurol. 1970; 23:314-318.

7. DeLevie M, Nogrady MB. Rapid brain growth upon restoration of adequate nutrition causing false radiologic evidence of increased intracranial pressure. J Pediatr 1970; 76:523-528.

8. Katznelson D. Increased intracranial pressure in cystic fibrosis. Acta Paediatr Scand. 1978; 67:607-609.

9. Roach ES, Sinal SH. Initial treatment of cystic fibrosis, frequency of transient bulging fontanel. Clin Pediatr. 1989; 28:371-373.

10. Kerem E, Corey M, Kerem B-S, et al. The relation between genotype and phenotype in cystic fibrosis-Analysis of the most common mutatation ( $\Delta$ F508). N Engl J Med. 1990; 323:15171522 . 